\title{
Primary Congenital Glaucoma among the Children Under 3 Years of Age in the Outpatient Department in a Tertiary Care Hospital: A Descriptive Cross-sectional Study
}

\author{
Rakshya Panta Sitoula, ${ }^{1}$ Jamuna Gurung, ${ }^{2}$ Afaque Anwar ${ }^{3}$ \\ 'Department of Glaucoma, Biratnagar Eye Hospital, Biratnagar, Nepal, ${ }^{2}$ Department of ophthalmology, Gandaki \\ Medical College and Teaching Hospital, Pokhara, Nepal, ${ }^{3}$ Department of Medical Education, Biratnagar Eye \\ Hospital, Biratnagar, Nepal.
}

\begin{abstract}
Introduction: Primary congenital glaucoma is a rare vision-threatening condition of children. Primary congenital glaucoma though a rare disease it is the most common cause of childhood glaucoma with potency to cause blindness. This study was undertaken to find the prevalence of the children with primary congenital glaucoma under 3 years of age in a tertiary care hospital.

Methods: This was a descriptive cross-sectional study conducted at a tertiary eye center in Nepal in children ( $\leq 3$ years) presented in the outpatient department of a tertiary eye hospital between June 2017 and June 2020. The study was approved by the hospital review committee and adhered to the declaration of Helsinki. A convenient sampling method was used. Point estimate at $90 \%$ Confidence Interval was calculated with frequency distribution. Data analysis was conducted using Statistical Package for the Social Sciences.
\end{abstract}

Results: Out of total children under 3 years who presented to the outpatient department, $46(0.31 \%)$ at $90 \%$ Confidence Interval (0.303-0.316) had primary congenital glaucoma. Among them, 30 children $(65.2 \%)$ had bilateral involvement. Mean intraocular pressure was $42.40 \pm 8.15 \mathrm{~mm} \mathrm{Hg}$. The mean age of initial presentation, horizontal corneal diameter, and axial length were $12.07 \pm 8.9$ months, $12.95 \pm 1 \mathrm{~mm}$, and $23.89 \pm 1.7 \mathrm{~mm}$ respectively. Consanguinity was observed in $12(26 \%)$ children.

Conclusions: From the study, we conclude that there was a low prevalence of primary congenital glaucoma among children under 3 years of age who presented to the outpatient department in a tertiary care hospital.

Keywords: buphthalmos; intraocular pressure; primary congenital glaucoma; trabeculectomy; trabeculotomy.

\section{INTRODUCTION}

Primary congenital glaucoma (PCG) is a developmental anomaly of anterior chamber angle leading to the increase in intraocular pressure (IOP), corneal edema, Habb striae, increased corneal diameter, buphthalmos, and optic nerve damage. ${ }^{1}$ PCG is common in certain ethnic and religious groups where parental consanguinity is prevalent. ${ }^{2-3}$ The incidence of PCG is reported to be 1 in 10,000-20,000,1 in 3300, 1 in 3030, 1 in 2500, 1 in 1200 live births in the western world ${ }^{4}$ Southern India, ${ }^{5}$ Saudi Arabia, ${ }^{6}$ Middle East ${ }^{7}$ and Slovakian Gypsies ${ }^{8}$ respectively.
PCG though a rare disease it is the most common cause of childhood glaucoma with potency to cause blindness. Goniotomy, ${ }^{9,10}$ trabeculotomy, ${ }^{11,12}$ and combined trabeculectomy with trabeculectomy have proven to be highly successful treatment modalities. ${ }^{13-17}$

There are lacunae in the literature addressing the scenario of children with congenital glaucoma in Nepal.

Correspondence: Dr. Rakshya Panta Sitoula, Head of Department of Glaucoma, Biratnagar Eye Hospital Biratnagar, Nepal. Email: rakshya.sitoula@erec-p.org, Phone: +9779842322600. 
This study was undertaken to find the prevalence of the children with primary congenital glaucoma under 3 years of age in a tertiary care hospital.

\section{METHODS}

This was a descriptive cross-sectional study conducted at a tertiary care ophthalmology center. Data were collected from the hospital record of all children $\leq$ 3 years of age that presented to OPD between June 2017 and June 2020. The study was approved by the Ethical review committee of the hospital, and adhered to the declaration of Helsinki. All the children below 3 years having complete data were included in this study. Children with incomplete clinical records were excluded from the study. Vision in these children is difficult to assess as most of them were preverbal so visual acquity was not included in the study. A convenient sampling method was used.

The sample size was calculated by using formula: $\mathrm{n}=\mathrm{Z}^{2} \times \mathrm{p} \times \mathrm{q} / \mathrm{e}^{2}$

$=(1.645)^{2} \times(0.5)(1-0.5) /(0.01)^{2}$

$=6765$

Where,

$\mathrm{n}=$ required sample size

$\mathrm{Z}=1.645$ at $90 \%$ Confidence Interval

$p=$ prevalence required for maximal sample size, $50 \%$

$q=1-p$

$\mathrm{e}=$ margin of error, $1 \%$

Here the calculated sample size is 6765 . After doubling the calculated sample size, the new sample becomes 13530. However, we have included 14614 children under 3 years visiting the outpatient department of a tertiary eye hospital for the study. Diagnosis of primary congenital glaucoma was made only after examination under anesthesia (EUA) as per guidelines given by Congenital Glaucoma Research Network (CGRN) guideline. ${ }^{18}$

All the records of the patients are filed in the glaucoma department and patients are discharged with the discharge summary. So, the data was taken from the hospital sheets which included EUA findings. A detailed history and demographic findings obtained at the first visit were recorded. History included duration of symptom, antenatal history, family history and consanguinity. Consanguinity was defined by a relationship by blood where parents or grandparents were first- or second-degree cousins.

Clinical examination data records were obtained from the EUA record sheets. Anesthesia used was ketamine with spontaneous ventilation. IOP was measured using tonopen (Reichert Technologies, Depew, New York, USA). EUA records included corneal diameter, corneal findings, Haab striae, iris and anterior chamber abnormalities, lens anomalies, cup to discratio, and axial length. Fundus findings were recorded only if corneal cloudiness did not preclude the visibility. Combined trabeculotomy with trabeculectomy (CTT) was carried out in one eye in the same sitting after completing clinical examination under anesthesia. All these children underwent trabeculotomy with trabeculectomy as all these children had hazy cornea which made goniotomy difficult.

Informed consent for surgical intervention was taken from the parents prior to subjecting the child for EUA and surgical intervention. Postoperatively during subsequent follow up ocular findings, intraocular pressure, optic disc findings and axial length recorded. Additional Informed consent was taken from the parent of all the children whose data were collected. Data analysis was conducted using Statistical Package for the Social Sciences.

\section{RESULTS}

Out of total 14614 children under 3 years, $46(0.31 \%)$ at $90 \%$ Confidence Interval (0.303-0.316) children diagnosed with primary congenital glaucoma.

The mean IOP of all the children at baseline was $42.40 \pm 8.15 \mathrm{~mm} \mathrm{Hg}$. There were 31 (67.39\%) male and $15(32.6 \%)$ female children, the ratio being 2:1. Thirty children $(65.2 \%)$ had bilateral involvement. Hence altogether there were 76 (82.06\%) ( $n=96)$ eyes that underwent Combined trabeculectomy and trabeculotomy whose data was analyzed.

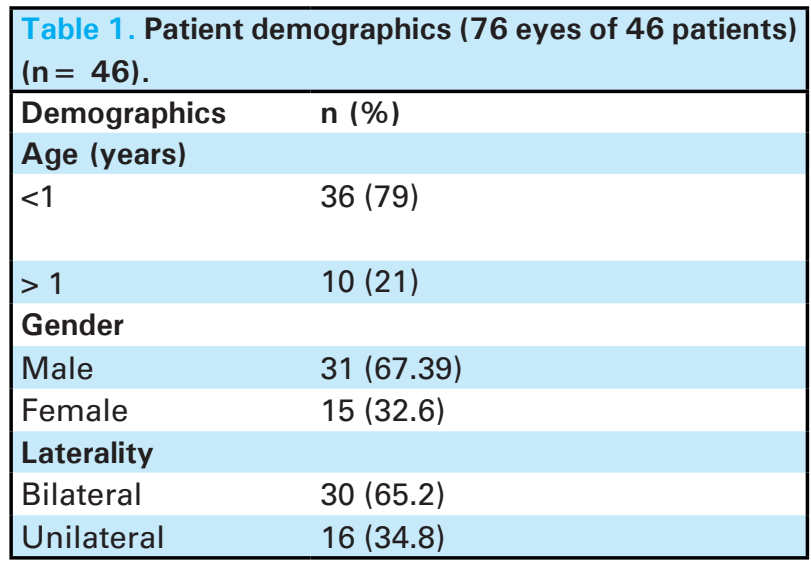

Mean age of initial consultation was $12.07 \pm 8.9$ months. Majority of the children presented within 1 year of age 36 (79\%). Family history of Glaucoma was recorded in two children where their elder sibling had congenital glaucoma. Consanguinity was seen in 12 (27\%) of the children.

Mean horizontal corneal diameter was $12.97 \pm 0.99 \mathrm{~mm}$ (Table 2). The axial length at presentation was $(23.89 \pm 1.79)$. It was not possible to evaluate the cup 
disc ratio in the entire child preoperatively due to corneal haziness. In the children where C/D ratio could be assessed the mean cup disc ratio was $0.7 \pm 0.22$ preoperatively. All the diagnosed children with PCG after EUA underwent same operative procedure combined trabeculotomy with trabeculectomy under general anesthesia.

\begin{tabular}{|ll|}
\hline \multicolumn{2}{|l|}{ Table 2. Clinical features on initial examination. } \\
\hline Clinical features & Mean \pm SD \\
Corneal diameter $(\mathrm{mm})$ & $12.95 \pm 0.99$ \\
Age of initial consultation (months) & $12.07 \pm 8.9$ \\
Preoperative IOP $(\mathrm{mm} \mathrm{Hg})$ & $42.40 \pm 8.15$ \\
Initial axial length & $23.89 \pm 1.79$ \\
Initial cup-disc ratio & $0.7 \pm 0.22$ \\
\hline
\end{tabular}

Complete success (IOP $\leq 21 \mathrm{~mm} \mathrm{Hg}$ without additional medication) was achieved in $52(68 \%)$ of the eye that underwent surgery at 1 year of follow up. Relative success was achieved IOP $<21 \mathrm{~mm} \mathrm{Hg}$ with 1 topical antiglaucoma medication in 62 (81.5\%) of the children.

\section{DISCUSSION}

This information obtained after analyzing the hospital record of children presenting to Biratnagar Eye Hospital with congenital glaucoma was of enormous importance. As this hospital is the main referral center for all the children with congenital glaucoma in the eastern region of Nepal this study was successful in establishing the scenario of congenital glaucoma in this region. Further, the importance of this study is enhanced by the fact that there is no published data on the date of congenital glaucoma in this region. In our study the primary congenital glaucoma was present in $46(0.39 \%)$ children under 3 years.

In our study congenital glaucoma was found to affect the male child more than female: $67.39 \%$ and $32.6 \%$ respectively. Similarly, various studies have shown male predominance. ${ }^{3,4,19}$ However, a recent study from Saudi Arabia showed an equal sex distribution. ${ }^{6}$ Majority of the children had bilateral disease (65.2\%) which is in consistency with the previous literatures of $70 \%$ to $80 \%{ }^{1-4,6}$

Mean age of initial consultation was 12 months similar to a multicentered study by Papadopoulos, et al. (11.3 months) ${ }^{3}$ but delayed as compared to a study by Alanazi, et al. ${ }^{6}$ where the mean age was 3.9 months. Majority of the children were brought by the parents within 1 year of age (79\%) which is consistent with various literatures. ${ }^{4,20}$ However, only $27 \%$ (13/48) of our cohort presented within 6 months of age though most of the parents noticed the haziness of cornea since 1-2 month of birth. This delay in initial presentation may be due to lack of awareness about congenital glaucoma among the parents of these children. When inquired specifically they told that they were in conception that small infants are not operated unless they are 1 year of age. As time of surgical intervention is very crucial it is essential that general Ophthalmologist and general practitioners are aware of this condition. In some developing countries like Ethopia the children with congenital glaucoma from rural regions presented at as late as 3 years of age. ${ }^{21}$

Family history was positive in only $3 / 46(6 \%)$ children which is in lower than the published literature ${ }^{4,6,20,22}$ which gives a range from $10 \%$ to $40 \%$. All three children had first degree cousin with congenital glaucoma and history of consanguineous marriage was positive. Various literature has shown an association between the incidence of congenital glaucoma and

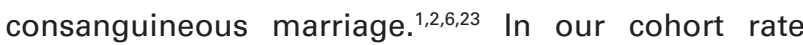
of consanguineous marriage was $27 \%$, and all these children belonged to one specific religious group where cousin-cousin marriage is practiced. Study from Saudi Arabia ${ }^{6}$ showed consanguineous marriage to be as high as $59 \%$ of the children. The British Infantile Glaucoma study ${ }^{3}$ found that $16 \%$ of their cohort was born of consanguineous marriage and all were of Asian origin ( $67 \%$ were Pakistanis). This evidence highlights the importance of community education about drawbacks of consanguineous marriage, genetic counseling of the couples and screening of siblings is recommended in communities where cousin - cousin marriage is practiced.

All eyes underwent single operation; CTT without Mitomycin C (MMC). We were able to achieve postoperative IOP of $\leq 21 \mathrm{~mm} \mathrm{Hg}$ in $65 \%(78 \%$ with medication) of the children after CTT which is comparable to other literatures. ${ }^{3,6,15,17}$ CTT was chosen initially instead of goniotomy or trabeculotomy alone because many studies have shown that CTT has shown the better IOP control. ${ }^{13-14,17,22}$ especially with advanced disease severity. ${ }^{24}$

The limitations of the study are that it is a descriptive cross-sectional study with biases. We cannot calculate the prevalence of congenital glaucoma in this region of Nepal as significant number of patients was from north-eastern regions of India. We addressed only PCG and had to exclude the SCG because of lack of hospital records of all these children. We cannot comment on long term results of the surgery.

\section{CONCLUSIONS}

From the study, we conclude that there was a low prevelance of family congenital glaucoma among children under 3 years of age who presented to the outpatient department in a tertiary care hospatal.

\section{Conflict of Interest: None.}




\section{REFERENCES}

1. Mandal AK, Chakrabarti D. Update on congenital glaucoma. Indian J Ophthalmol 2011:59(Suppl):S148-57. [PubMed | $\underline{\text { Full Text }}$ DOI]

2. Genicek A, Genicekova A, Ferak V. Population genetical aspects of primary congenital glaucoma. Incidence, prevalence, gene frequency, and age of onset. Hum Genet. 1982;61:193-7. [ㄹuMed | Full Text | DOI]

3. Papadopoulos M, Cable N, Rahi J, Khaw PT. The British Infantile and Childhood Glaucoma (BIG) Eye Study. Invest Ophthalmol Vis Sci. 2007 Sep;48(9):4100-6. [PubMed | Full $\underline{\text { Text }} \mid \underline{\mathrm{DOI}}]$

4. McGinnity FG, Page AB, Bryars JH. Primary congenital glaucoma: twenty years experience. Ir J Med Sci. 1987 Dec;156:364-5. [PubMed | Full Text | DOI]

5. Dandona L, Williams BC, Rao GN. Population-based assessment of childhood blindness in Southern India. Arch Ophthalmol. 1998;116:545-6. [PubMed]

6. Alanazi FF, Song JC, Mousa A, Morales J, Al Shahwan S, Alodhayb $S$, et al. Primary and Secondary Congenital Glaucoma: Baseline features from a registry at King Khaled Eye Specialist Hospital, Riyadh, Saudi Arabia. Am J Ophthalmol. 2013 May;155(5):882-9. [라Med | Full Text | DOI]

7. Challa P. Glaucoma genetics. Int Ophthalmol Clin. 2008 Fall;48(4):73-94. [Full Text | DOI]

8. Genĉík A. Epidemiology and genetics of primary congenital glaucoma in Slovakia. Description of a form of primary congenital glaucoma in gypsies with autosomal-recessive inheritance and complete penetrance. Dev Ophthalmol. 1989;16:76-115. [PubMed]

9. Shaffer RN. Prognosis of goniotomy in primary infantile glaucoma (trabeculodysgenesis). Trans Am Ophthalmol Soc. 1982;80:321-5. [PubMed]

10. Broughton WL, Parks MM. An analysis of treatment of congenital glaucoma by goniotomy. Am J Ophthalmol. 1981;91:566-72. [uuMed | Full Text | DOI]

11. Luntz MH. The advantages of trabeculotomy over goniotomy. J Pediatr Ophthalmol Strabismus. 1984;21:150-3. [PubMed]

12. McPherson SD, Berry DP. Goniotomy vs external trabeculotomy for developmental glaucoma. Am J Ophthalmol 1983;95:427-31. [PubMed | Full Text | DOI]
13. Elder MJ. Combined trabeculotomy-trabeculectomy compared with primary trabeculectomy for congenital glaucoma. Br J Ophthalmol. 1994;78:745-8. [람ed | Full $\underline{\text { Text }}$ | DOI]

14. Mullaney PB, Selleck, Al-Award A, Al-Mesfer S, Zwaan J. Combined trabeculotomy and trabeculectomy as initial procedure in uncomplicated congenital glaucoma. Arch Ophthalmol 1999;117:457-60. [․ㅏbMed | Full Text | DOI]

15. Mandal AK, Naduvilath TJ, Jayagandhan A. Surgical results of combined trabeculotomy-trabeculectomy for developmental glaucoma. Ophthalmology 1998;105:974-82. [PubMed | Full Text | DOI]

16. O'Connor G. Combined trabeculotomy-trabeculectomy for congenital glaucoma. Br J Ophthalmol. 1994;78:735. [PubMed | Full Text | DOI]

17. Mandal AK, Gothwal VK, Nutheti R. Surgical outcome of primary developmental glaucoma: A single surgeon's long-term experience from a tertiary eye care center in India. Eye 2007;21: 764-74. [ㄹuMed | Full Text | DOI]

18. Beck AD, Chang TCP, Freedman SF. "Definition, Classification, Differential Diagnosis." Childhood Glaucoma: Consensus Series 9. Amsterdam: Kugler; 2013 [cited 2021 Aug 8]. Available from: https://wga.one/wga/ consensus-9/. [ [Full Text]

19. Barsoum-Homsy M, Chevrette L. Incidence and prognosis of childhood glaucoma: a study of 63 cases. Ophthalmology. 1986;93:1323-7. [PubMed | Full Text | DOI]

20. Gramer E, Tausch M, Kraemer C. Time of diagnosis, reoperations and longterm results of goniotomy in the treatment of primary congenital glaucoma: a clinical study. Int Ophthalmol. 1997;20:117-23. [PubMed | Full Text | DOI]

21. Moore BD, Tomkins O, Ben-Zion I. A review of Primary Congenital Glaucoma in the Developing World. Surv Ophthal 2013;58:278-85. [ㅁubMed | Full Text | DOI]

22. Francois J. Congenital glaucoma and its inheritance. Ophthalmologica. 1980;181:61-73. [P PubMed | Full Text | DOI]

23. Turacli ME, Aktan SG, Sayli BS, Akarsu N. Therapeutic and genetical aspects of congenital glaucomas. Int Ophthalmol. 1992;16:359-62. [ubMed | Full Text | DOI]

24. Al-Hazmi A, Awad A, Zwaan J, Al-Mesfer SA, AI-Jadaan I, AI-Mohammed A, et al. Coreelation between surgical success rate and severity of congenital glaucoma. $\mathrm{Br} J$ Ophthalmol 2005;89(4):449-53. [PubMed | Full Text | DOI]

\section{(c) The Author(s) 2018.}

This work is licensed under a Creative Commons Attribution 4.0 International License. The images or other third party material in this article are included in the article's Creative Commons license, unless indicated otherwise in the credit line; if the material is not included under the Creative Commons license, users will need to obtain permission from the license holder to reproduce the material. To view a copy of this license, visit http://creativecommons.org/licenses/by/4.0/ 